\title{
Reliability evaluation of distribution networks incorporating cable electro-thermal properties
}

DOI:

10.1109/PSCC.2016.7541003

\section{Document Version}

Submitted manuscript

Link to publication record in Manchester Research Explorer

\section{Citation for published version (APA):}

Liu, S., \& Kopsidas, K. (2016). Reliability evaluation of distribution networks incorporating cable electro-thermal properties. In Power Systems Computation Conference (PSCC) (pp. 1-7). IEEE.

https://doi.org/10.1109/PSCC.2016.7541003

\section{Published in:}

Power Systems Computation Conference (PSCC)

\section{Citing this paper}

Please note that where the full-text provided on Manchester Research Explorer is the Author Accepted Manuscript or Proof version this may differ from the final Published version. If citing, it is advised that you check and use the publisher's definitive version.

\section{General rights}

Copyright and moral rights for the publications made accessible in the Research Explorer are retained by the authors and/or other copyright owners and it is a condition of accessing publications that users recognise and abide by the legal requirements associated with these rights.

\section{Takedown policy}

If you believe that this document breaches copyright please refer to the University of Manchester's Takedown Procedures [http://man.ac.uk/04Y6Bo] or contact uml.scholarlycommunications@manchester.ac.uk providing relevant details, so we can investigate your claim.

\section{OPEN ACCESS}




\section{Reliability Evaluation of Distribution Networks Incorporating Cable Electro-Thermal Properties}

\author{
Shuran Liu \\ Electrical Energy and Power System Group \\ School of Electrical and Electronic Engineering \\ The University of Manchester \\ Manchester, UK \\ shuran.liu@manchester.ac.uk
}

\author{
Konstantinos Kopsidas \\ Electrical Energy and Power System Group \\ School of Electrical and Electronic Engineering \\ The University of Manchester \\ Manchester, UK \\ k.kopsidas@manchester.ac.uk
}

\begin{abstract}
Power utilities are pursuing ways to improve the utilization and efficiency of network infrastructure, and to develop a strategic maintenance and replacement plan for their infrastructure. Underground cables require a significant time on such maintenance and replacement planning. Utilities could increase their network utilization and operation efficiency by employing the intrinsic ability of cables to tolerate emergency ratings. This ability comes from the thermal inertia of the cable system, which significantly delays the increase in cable temperature after an increase in current. This paper introduces a new network reliability evaluation coupled with cable electrothermal modelling. Thus, it captures cable system properties in combination with its surroundings (soil) conditions to allow the evaluation of cable emergency ratings within reliability assessments. This approach can help utilities to identify the critical loaded cables and provide a network-wide thermal loading map enabling more informed decisions on optimal cable maintenance and replacement.
\end{abstract}

Index Terms - underground cables, distribution networks, cable thermal modelling, reliability assessment

\section{INTRODUCTION}

The need for increasing the penetration of renewable energy sources has forced power utilities to improve the utilization and efficiency of their network infrastructure. Since there is a significant amount of power cables in power transmission and distribution networks, optimising their operation and utilization will help utilities to achieve this goal. Therefore, strategic maintenance and replacement plans for cables should be made [1]. Thermal profiles of cables in the network would help utilities to estimate more accurately the thermal loading conditions of cables and help them to identify the critical cables within a network. Thus will providing more informed suggestions on optimal cable maintenance and replacement strategies.

Underground Cables (UGCs) have a significant time delay of temperature elevation after an increased current level occurs due to thermal inertia of the cable and its surroundings [2]. This thermal inertia is frequently neglected in the steady- state thermal modelling resulting in lower actual cable temperatures in most operating conditions for which utilities have designed their systems [3]. Transient thermal modelling considers the thermal inertia of the cable systems and therefore allows to more accurately evaluate cable operational thermal profile [4]. Several methods have been developed to calculate the cable temperature. Finite element analysis deemed as more accurate since it allows the geometrical and material properties, can also be used but it requires high computational times [5]. Other computational methods are based on current measurements and cable lumped parameters within a Thermo-Electric Equivalents (TEE) model. This method has been proven sufficiently accurate for both steady and transient state analyses when modelling standard installations [6].

Cables in general can tolerate emergency loading temperatures, which are substantially higher than normal loading temperatures. However, those temporary emergency loadings can be tolerated for moderate periods and in some cases, at the expense of an admissible percentage of life loss [7]. Therefore, UGCs are designed with the capability to tolerate emergency ratings under emergency operation. Both IEEE [7] and IEC [8] provide models that capture cable capabilities and they are also acknowledged by most cable manufacturers and utilized by power utilities [9].

Currently an attempt to further improve the modelling of single cables particularly under emergency rating capabilities is investigated in $[10,11]$. However, there is limited work investigating the network reliability with the implementation of cable emergency rating capability within a network-wide performance. The electro-thermal modelling of overhead lines into a network-wide reliability evaluation is evaluated in [12]. The impact of dynamic thermal rating of cables into network reliability assessment, which includes an electro-thermal modelling of cables, is studied in [13, 14]. However, most of this work does not consider the thermal inertia into the thermal modelling which is one the most dominant design factors. 
This paper introduces a network reliability evaluation that is coupled with the TEE model of cables permitting the inclusion of emergency loadings. The proposed methodology, therefore, captures cable and ducting system properties in combination with surrounding environmental (soil) conditions. This provided the basis for a more accurate calculation of cable thermal profiles within a network. An implementation of this methodology on a standard IEEE RBTS bus 4 distribution network is also illustrated.

\section{RELIABILITY EVALUATION INCORPORATING CABLE ELECTRO-THERMAL PROPERTIES}

\section{A. Outline of proposed methodology}

The proposed methodology is outlined in Fig.1. Input data describing the plant and the network characteristics are fed into the block of 'system state initialization'. Network data describe the normal failure and repair rates of each network component, transformers' maximum ratings and impedances, cable maximum normal and emergency ratings and impedances, as well as the load points' chronological demand. The transition time step, $\Delta t$, is specified as the transition time of the network component state, weather data and power demand, which influences the accuracy of the analysis and simulation speed. Plant data consider the ambient soil temperature, which can be obtained from weather stations, as well as data that describe cable type, size, and laying conditions

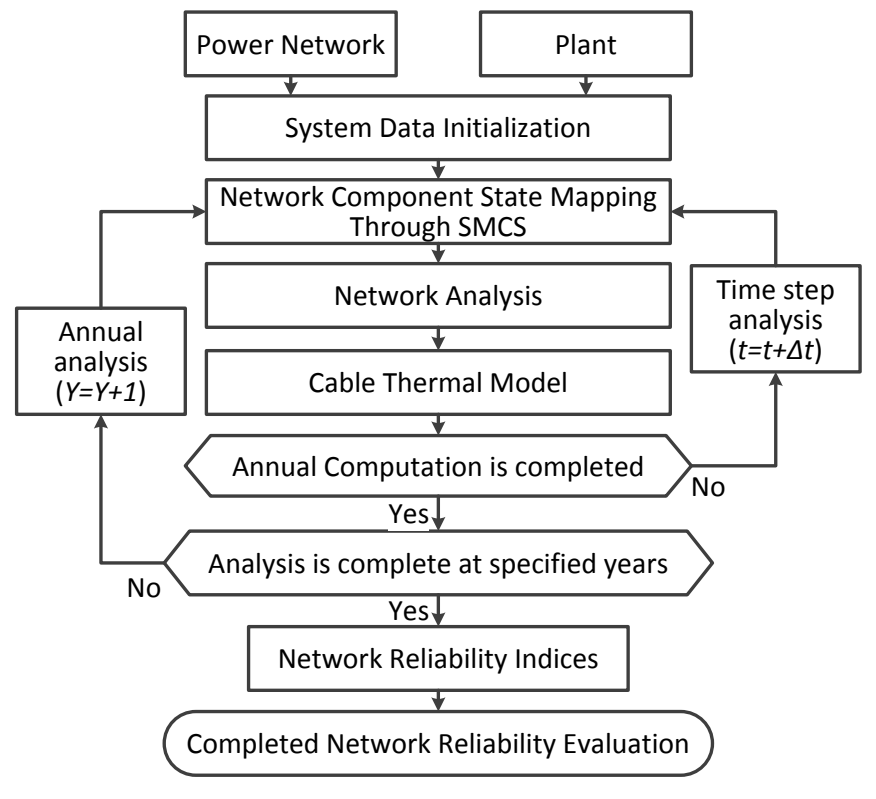

Figure 1. Outline of proposed methodology

The 'network component state mapping through SMCS' block builds the operation and restoration transition of component states for every element in the network. In addition, it creates the demand profile for each load point and the weather changes are mapped for every $\Delta t$ in a year through Sequential Monte Carlo (SMC) algorithm. This procedure utilises the input reliability data (e.g., failure rates, $\lambda$, and average repair durations, $R$,) as well as loading and generating profiles for network components. The process of state sampling and mapping through SMC has been described in detail in $[15,16]$, and it is not described here.

System analysis is then performed in two main iterative computational loops. One is implemented to perform network operation analysis for each $\Delta t$, while the other loop performs the annual reliability computations.

The simulations are performed in an annual iteration loop that generates a new operation and restoration sequences of network components at the beginning of each year. The simulation is completed once the annual simulations have been repeated for the completed specified number of years. Based on the results from network analysis, the calculated indices are updated.

Once the simulation is complete, network reliability indices will be calculated. Those are Expected Energy Not Supplied (EENS), Average Energy Not Supplied (AENS), System Average Interruption Duration Index (SAIDI), System Average Interruption Frequency Index (SAIFI), Customer Average Interruption Duration Index (CAIDI), Average Service Availability Index (ASAI) and Average Service Unavailability Index (ASUI). The mathematical formulations of the calculated indices can be found in [15].

\section{B. Network restoration process with emergency ratings}

Cable emergency ratings are defined for each cable in the network and represented as $I_{E}$. Emergency ratings are calculated based on IEEE and IEC in $[7,8]$ considering emergency loading temperature, ambient soil temperature, cable preloading, the duration of emergency rating, laying conditions and cable design properties. A conservative hypothesis of $100 \%$ preloading is used in the calculation of emergency rating as it is a common practice for cable manufacturers and utilities [9]. The maximum per overload duration is set to 36 hours in [7] which is used as the duration of emergency rating in the calculation. Such conservatism avoids cable ageing and reduces the failure risk of cables during the emergency loading.

In the block of 'network analysis', ACPF computations are performed for the network configuration at each $\Delta t$ time-step. When a fault occurs, contingency emergency steps need to restore service to as many affected customers as possible using both switching actions and cable emergency loading.

Once a fault occurs in the network and the location of a fault is identified, sectionalising devices operate to isolate the fault (e.g., disconnecting switches). The supply to upstream area customers is restored through the main supply by reclosing the upstream circuit breaker after fault isolation. The downstream customers are restored by closing the tie-switch through the supply from the neighbouring feeder.

Once the restoration is established, distribution cables on the neighbouring feeder usually operate close to their capacity limits and in some occasions could be temporarily overloaded. Under these circumstances the emergency ratings are employed to allow for increased loading during emergency restorations. When there is no overloading during a fault, no further network operations are considered. However, when an overloading of a cable is determined the tie-switch is opened 
and stay opened, until the fault is restored. This therefore, interrupts all loads on the restored downstream area. In this case an updated network analysis is performed using ACPF on the new network configuration of the same time step. The final computed cable currents are fed into the 'cable thermal model' block in order to calculate the final temperatures for this time step.

\section{Thermal modelling of cables}

\section{1) Outline of thermal modelling for cable system}

The block of 'cable thermal model' in Fig.1 indicates the cable temperature calculation within the complete network reliability analysis. This block is utilised for both transient and steady state thermal modelling, described in Fig. 2 with a more detailed flowchart.

The input data for these calculations are fed into the block of 'cable system data'. This includes, cable design configuration and technology/material properties that describe the cable type (e.g., paper or XLPE), cable size, phases (single core or three cores), internal configuration (with or without armour) and the material for each layer and its thermal properties (thermal resistances and capacitances). Further information related to laying formation and installation depth as well as soil temperature are also included.

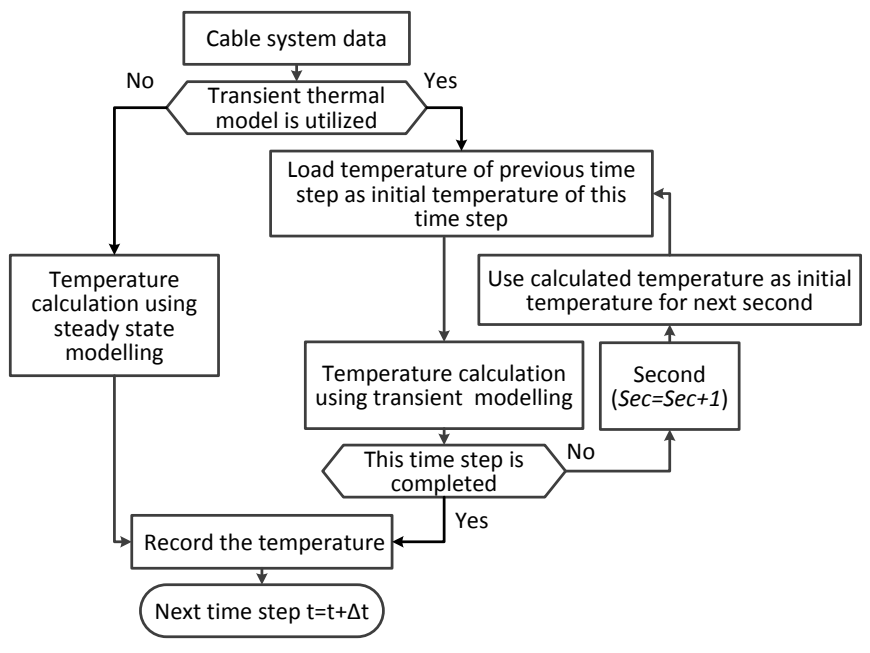

Figure 2. Flowchart of cable thermal model

The cable system data then is fed into the TEE steady state and transient thermal models to calculate the conductor temperature at the end of the time step.

Steady state conductor temperature of each cable is calculated by feeding all input data into the steady state thermal model. However, the transient temperature calculation requires the final conductor temperature of the previous time step set as the initial temperature of this time step in order to compute the final transient temperature for the current time step. This transient calculation is based on an iterative calculation with a minute repetitions (i.e., for a single hour time step analysis 60 iteration will be performed to calculate the final transient temperature). The final cable temperature is registered as the temperature of that time step. Thus, it considers an additional level of conservatism in the modelling.

\section{2) TEE method implemented}

Considering the low computational time and the compatibility with SMCS, a method solely based on current measurement and the TEE model [3] was chosen to provide temperature estimation for cables. The TEE method, based on electrical lumped parameter models, considers thermal model of the cable and surrounding soil as an analog of the electric circuit. In this TEE circuit, electrical resistances and capacitances represent series thermal resistances and shunt thermal capacitances, and heat sources are inserted into the network as current sources. Steady state thermal modelling of cables can be obtained by neglecting all capacitances, while transient thermal model needs to include the thermal capacitances of cable components and the surrounding soil.

In the methodology, a multi-layer soil model using an exponential discretization approach is utilized to subdivide the surrounding soil into layers; this means that numerous and thin layers are preferable near the cable and thicker layers are sufficient in the far regions of the soil [17]. Each soil layer is modelled by a $\mathrm{T}$ equivalent circuit with its thermal resistance Ts and capacitance Cs. The exponential discretization of the soil is expressed in (1)-(2) where $b_{i}$ are the radial position of the layer borders, $r_{c}$ is the radius of the cable, $N$ is the number of layers, $d_{m}$ is the depth of the model, $i$ is $0,1, \ldots, N$, and $\gamma$ is the argument of the exponential distribution.

$$
\begin{gathered}
b_{i}=r_{c}+\left(d_{m}-r_{c}\right) \cdot \frac{e^{\gamma \cdot i}-1}{e^{\gamma \cdot N}-1} \\
d_{m}=L+\sqrt{L^{2}-r_{c}^{2}}
\end{gathered}
$$

This optimal soil model based on discretization methods helps to reduce the number of soil layers, which helps to reduce simulation time while maintaining accuracy. An example of a simple TEE circuit is shown in Fig.3 for an unarmoured cable with 5 soil layers.

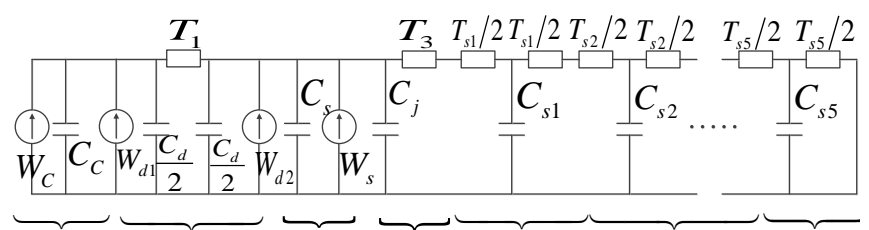

$\underbrace{}_{\text {Conductor }} \underbrace{\text { Insulation Screen Inrket }}_{\text {Insulation }} \underbrace{\overbrace{\text { Soil I.aver 2.3and } 4}^{\underbrace{}_{\text {Soil I.aver } 5}}}_{\text {Soil Laver1 }}$ Figure 3. The thermo electric equivalents (TEE) with 5 soil layers of an unarmoured cable

As shown in Fig.3, conductor, insulating dielectrics, screen and jacket are represented by four layers. Therefore, $T_{1}$ and $T_{3}$ represent the thermal resistance of the insulating dielectrics and jacket, while $C_{c}, C_{d}, C_{s}$, and $C_{j}$ represent the thermal capacitances of the conductor, insulating dielectrics, screen, and jacket, respectively. Heat sources $W_{c}, W_{s}$ represent the losses in the conductor and screen, respectively. The dielectric losses are split into two: $W_{d 1}$ and $W_{d 2}$. All of these cable parameters together with the resistance and capacitance of each soil layer can be calculated according to [7, 8]. The temperatures at different subcomponent interfaces of a cable system will appear in TEE as voltages at different nodes. The required cable conductor temperature is obtained by the 
voltage at the conductor node. Therefore, available electrical circuit analysis techniques are able to provide differential solutions of TEE model and calculate the conductor temperature of the cable.

\section{CASE STUDY FORMULATION}

The proposed methodology is applied to the IEEE RBTS bus 4 distribution network in [18] with different demand levels to stress the network and encounter cable emergency loading. The analyses are performed by setting the SMC simulation for 1000 repetitions of annual modelling with time step $(\Delta t)$ segmentation of one hour.

\section{A. IEEE RBTS Bus 4 Test Network}

The test distribution system on which the proposed methodology is implemented is shown in Fig. 4; it consists of 7 feeders ( $F 1-F 7), 38$ load points ( $L P 1-F 38)$, disconnecting switches on both sides for each feeder cable and 4 tieswitches. The tie-switches (TS1-TS4) are open, while all other switches are closed in normal operation. The default peak load of the network is 0.8pu of the actual 40MW and 13MVar, load in [18]. The hourly chronological load profile described in [19] is used to describe the load profile for this network.

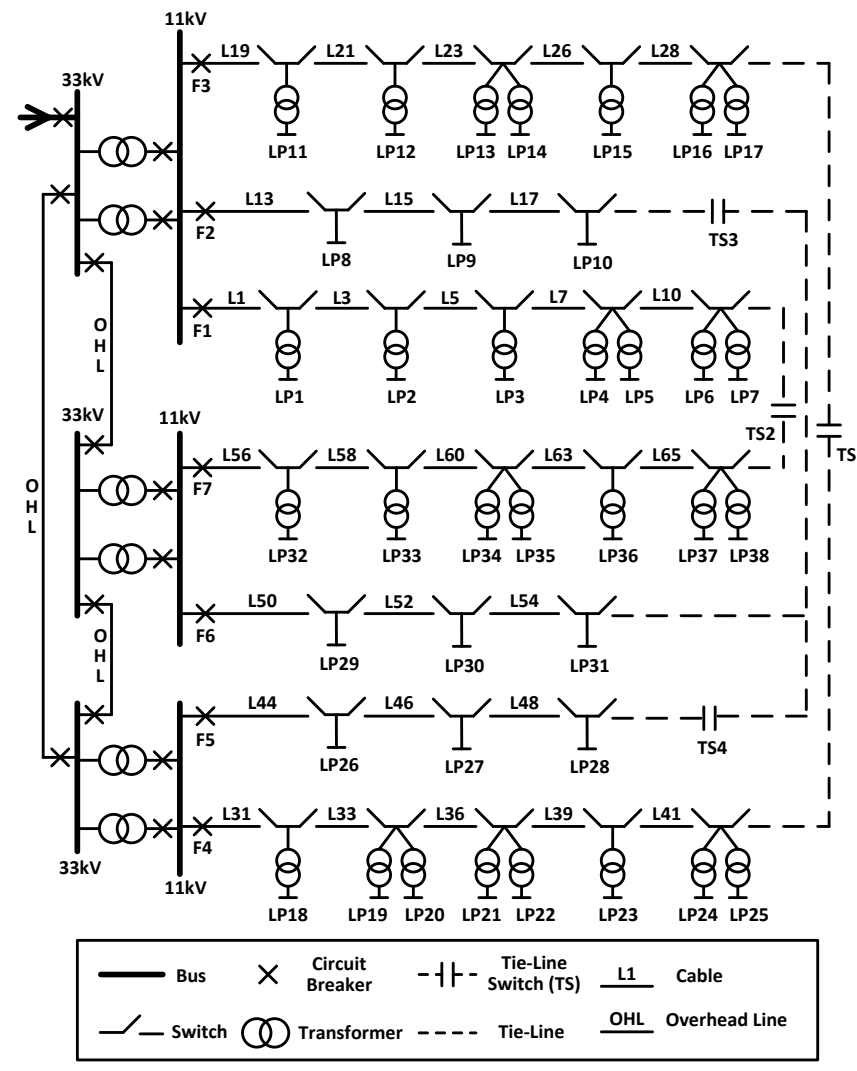

Figure 4. Test distribution system - IEEE RBTS bus 4

In order to evaluate the impact of cable overloading capability and exclude other influencing factors, only the feeder cables (numbered with $L$ ) are modelled to fail while all other network components are considered to be $100 \%$ reliable. The capacity of all these other network components is set high enough to not constraint the network in all studied scenarios. From reliability data provided in [18], the cables' annual failure rate is $\lambda=0.04 / \mathrm{yr} . \mathrm{km}$, and average repair time is $R=30$ hours. It is assumed that all the disconnecting switches and tieswitches are automated, therefore the fault isolation and service restoration through a tie-switch is very short and the duration of load interruption in this case is neglected in the analyses. However, the frequency of the load interruption is affected by this “instantaneous” smart switching.

\section{B. Test Cable Properties}

The study is performed using an $11 \mathrm{kv}$ three-core unarmoured XLPE cable with $300 \mathrm{~mm}^{2}$ cross-area copper conductor for all network cables. The cable has a $37.5 \mathrm{~cm}$ radius, $r_{c}$, and a $20.3 \mathrm{~mm}$ conductor diameter. Its XLPE thickness is $3.4 \mathrm{~mm}$ with a PVC oversheath thickness of 3.3 $\mathrm{mm}$. All cables are assumed to be buried directly at a depth $L=0.8 \mathrm{~m}$ with a $\rho_{T-S}=1.2 \mathrm{~km} / \mathrm{W}$ soil thermal resistivity (common for UK) and $C_{T-S}=2.064 \times 10^{6} \mathrm{~J} / \mathrm{m}^{3} \mathrm{~K}$. A constant ambient soil temperature of $15^{\circ} \mathrm{C}$ is assumed though out the year for simplicity.

The selected cable has a normal rating, $I_{N}$, of $560 \mathrm{~A}$ at $90^{\circ} \mathrm{C}$ normal operating temperature, $\theta_{N}$. Its emergency current rating, $I_{E}$, can be calculated using (3) adopted by IEEE [8]. Where, $I_{R}$ is rated current rating, $I_{1}$ is constant current prior to emergency, $\theta_{E}$ is conductor emergency operating temperature, $\theta_{a}$ is ambient soil temperature, $K$ is the thermal time constant and $t$ is time after start of overload in hours.

$$
I_{E}=I_{R} \cdot \sqrt{\frac{\left(\theta_{E}-\theta_{a}\right) /\left(\theta_{N}-\theta_{a}\right)-\left(I_{1} / I_{R}\right)^{2} \cdot \exp (-t / K)}{1-\exp (-t / K)} \cdot\left(\frac{230+\theta_{N}}{230+\theta_{E}}\right)}
$$

For this $300 \mathrm{~mm}^{2}$ section directly buried cable a $K=6$ is considered. The study also considers $100 \%$ preloading so $I_{1}=I_{R}$ with a $\theta_{a}=15^{\circ} \mathrm{C}$ and $t=36 \mathrm{~h}$ and $\theta_{E}=130^{\circ} \mathrm{C}$, which is the design emergency thermal loading of XLPE cables. When all the parameters are fed into the equation, the results show that the calculated $I_{E}$ is $1.169 \mathrm{pu}$ based on $I_{N}$. Therefore, $I_{E}=654 \mathrm{~A}$ is utilised for the cable of this study.

\section{Simulation Scenarios}

Four basic scenarios are implemented using the network in Fig. 4 considering demand of 1.5 and 2 times the default demand of [18] (i.e., $0.8 \mathrm{pu}$ ). Both steady state and transient state cable thermal modelling are applied for each scenario to evaluate the difference in cable thermal loading. All these four scenarios are shown in Table I.

TABLE I. SIMULATION SCENARIOS AND DESCRIPTIONS

\begin{tabular}{c|c}
\hline Scenario & Description \\
\hline Sc-1 & $\mathrm{k}=1.5$, No emergency rating \\
\hline Sc-2 & $\mathrm{k}=2$, No emergency rating \\
\hline Sc-3 & $\mathrm{k}=1.5$, emergency rating based on $I_{E}$ \\
\hline Sc-4 & $\mathrm{k}=2$, emergency rating based on $I_{E}$ \\
\hline
\end{tabular}




\section{RESUltS AND ANALYSIS}

The analysis of the results is performed on two distinct levels one describing the network complete performance and another one assessing the main cable thermal profiles.

\section{A. Assessment of Network Reliability Performance}

The computed outputs for the overall network performance are shown in Table II. The results in Table II indicate a reduced network performance when the network demand increases from 1.5 to 2 times compared to default demand. The EENS increases from 105.8 MWh/yr to 320.0 MWh/yr for the scenarios without the utilisation of the emergency rating operation, while it increases from $33.8 \mathrm{MWh} / \mathrm{yr}$ to 167.7 MWh/yr for the scenarios with emergency rating. Doubling the demand (to $2 \mathrm{pu}$ ) imposes more stress to the network causing cables to operate close to their capacity limits more frequently during normal operation. With twice the demand, the cables will become overloaded more frequently particularly after the restoration of load followed by a cable failure event. Therefore more load points will be interrupted after load restoration in both cases, i.e., with and without the inclusion of emergency loading, of network modelling. Consequently, a negative impact on network's reliability is captured.

The comparison of the outputs (Table II) from the scenarios that consider emergency rating against those without, indicate an improved network performance owing to the emergency rating utilisation of cables during emergency restorations. In particular, Sc-3 results in the lowest EENS and ASAI compared to all the other scenarios. Sc-4 also results in a greatly improved network performance compared with Sc-2. It is suggested that the emergency rating reduces the frequency and duration of customer interruptions as well. This illustrates that emergency rating of cables provides the network with additional flexibility and loadability during emergency operations. Thus, emergency rating reduce the impact of network constraints on load curtailment.

TABLE II. SUMMARY OF NETWORK RELIABILITY PERFORMANCE INDICES

\begin{tabular}{c|c|c|c|c|c|c|c}
\hline & $\begin{array}{c}\text { EENS } \\
\text { MWh/yr }\end{array}$ & $\begin{array}{c}\text { AENS } \\
\text { MWh/cus.yr }\end{array}$ & $\begin{array}{c}\text { SAIFI } \\
\text { int./cus.yr }\end{array}$ & $\begin{array}{c}\text { SAIDI } \\
\text { h/cus.yr }\end{array}$ & $\begin{array}{c}\text { CAIDI } \\
\text { h/int }\end{array}$ & ASAI & ASUI \\
\hline Sc-1 & 105.8 & $2.21 \mathrm{E}-02$ & 0.13 & 1.17 & 8.99 & 0.99987 & $1.3 \mathrm{E}-04$ \\
\hline Sc-2 & 320.0 & $6.70 \mathrm{E}-02$ & 0.40 & 1.88 & 4.65 & 0.99979 & $2.1 \mathrm{E}-04$ \\
\hline Sc-3 & 33.8 & $7.07 \mathrm{E}-03$ & 0.07 & 0.60 & 8.87 & 0.99993 & $6.9 \mathrm{E}-05$ \\
\hline Sc-4 & 167.7 & $3.51 \mathrm{E}-02$ & 0.18 & 1.56 & 8.51 & 0.99982 & $1.8 \mathrm{E}-04$ \\
\hline
\end{tabular}

In particular, it can be observed that the emergency rating of cables is more effective under a lower demand level mainly due to the reduced frequency of interruptions (SAIFI). In this network, the ASAI sees a larger increase between Sc-1 and Sc-3 (0.99987 to 0.99993) than between Sc-2 and Sc-4 (0.99979 to 0.99982). However, the EENS sees a larger decrease from Sc-2 to Sc-4 (320.0 MWh/yr to 167.7 MWh/yr) than from Sc-1 to Sc-3 (105.8 MWh/yr to 33.8 MWh/yr). This suggests that the implementation of emergency ratings on the modelling decreases the EENS more when the network is stressed more indicating that the value of overloading the cables at increased demand has higher reliability worth on overall network performance.

\section{B. Assessment of Cable Thermal Profile}

In order to reveal the impact of the employment of the emergency rating, the temperature profiles of $L 1$ in both Sc-1 and Sc-3 are displayed in Fig.5.

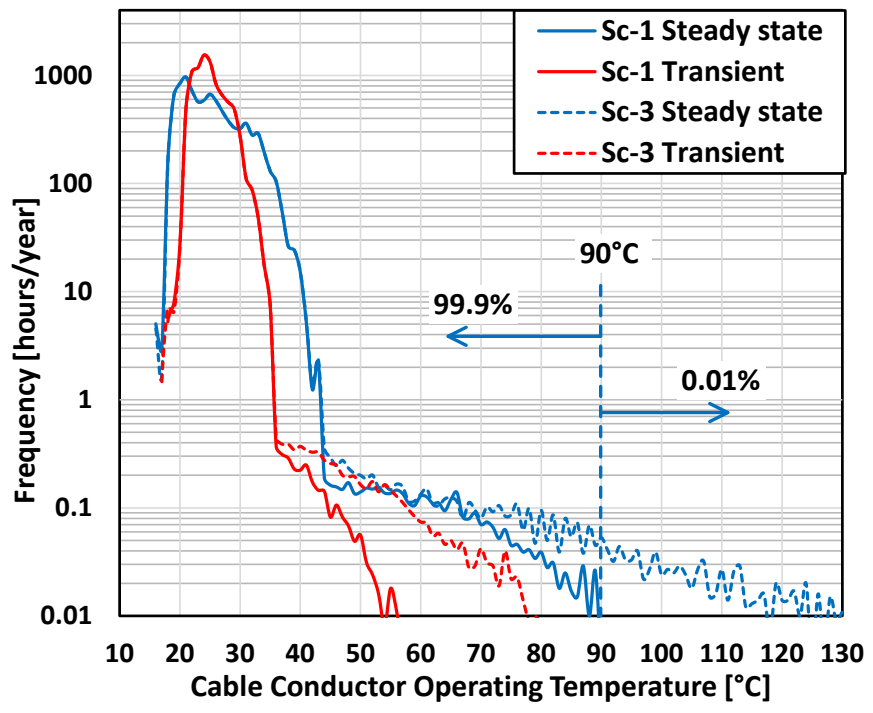

Figure 5. Temperature Distribution of $L 1$ for Sc- 1 and Sc-3

The frequency distributions of the $L 1$ cable operating temperature and the percentile below and above $90^{\circ} \mathrm{C}$ can be observed in Fig. 5. This temperature profile for cable L1 illustrates that there is a considerable increase in cable loading duration within the range of $45^{\circ} \mathrm{C}$ to $90^{\circ} \mathrm{C}$ compared to the increase in loading duration at above $90^{\circ} \mathrm{C}$. This results in increased benefit from higher loading of the cable compared to the negative impact on cable's life due to increased thermal stress of the cable (i.e., operation at $90^{\circ} \mathrm{C}$ and above).

In Table III, the mean value, the standard deviation as well as the percentile of the area above $90^{\circ} \mathrm{C}$ is shown for all the four scenarios profiles of Fig. 5 .

TABLE III. MEAN VALUE, STANDARD DEVIATION AND PERCENTILE ABOVE $90^{\circ} \mathrm{C}$ FOR THERMAL PROFILES IN FIG.5

\begin{tabular}{c|c|c|c}
\hline & Mean value, ${ }^{\circ} \mathrm{C}$ & $\begin{array}{c}\text { Standard } \\
\text { Deviation }\end{array}$ & Percentile $>90^{\circ} \mathrm{C}, \%$ \\
\hline Sc-1 Steady State & 25.11 & 4.91 & 0 \\
\hline Sc-1 Transient & 24.98 & 2.66 & 0 \\
\hline Sc-3 Steady State & 25.14 & 5.01 & 0.01 \\
\hline Sc-3 Transient & 24.99 & 2.72 & 0 \\
\hline
\end{tabular}

Comparing the transient with the steady state scenarios outputs in Fig.5 and Table III it can be concluded that the steady state temperature has a significantly wider variation range and larger standard deviation than the transient temperature. This indicates the steady state temperature is more dispersive due to its added conservatism when it is 
compared to the more realistic transient temperature. This difference will further increase when larger cables or different cable systems are used that provide increased thermal inertia.

Both transient and steady state modelling generate a similar minimum operating temperature which is around $15^{\circ} \mathrm{C}$, which is the ambient, indicating that they have been operating with zero current loading (i.e., experience an interruption). However the maximum operating temperature of Sc-1 is around $90^{\circ} \mathrm{C}$ in steady state modelling, while it is only around $55^{\circ} \mathrm{C}$ in the transient model. This is because the transient thermal model considers the thermal inertia which results in a significantly delayed temperature change after the variation of current levels. However the thermal inertia is neglected in the steady state thermal model, therefore it directly generates the final temperature solely based on cable current neglecting the entire thermal inertia of the cable and its surrounding. Therefore, transient thermal modelling of cables helps to provide more accurate and precise thermal profiles of cables.

It is indicated in Table III that transient temperatures do not exceed $90^{\circ} \mathrm{C}$ under emergency rating. However, the steady state temperature of Sc-3 over $90^{\circ} \mathrm{C}$ is in the percentile of $0.01 \%$ (average 0.86 hours per year) as indicated in Fig.5. These increased frequencies should in reality have an impact on the ageing and the failure rate of cables which is not captured in this paper. Considering that the operating duration of the cable over $90^{\circ} \mathrm{C}$ is very short, the risk of ageing caused by emergency rating should be tolerable and negligible for cables.

With the help of thermal modelling, the cable operating thermal profiles can be generated for each cable in the network. These can form the thermal loading map of the network to identify their criticality. In the test distribution network, the thermal profiles are computed for each feeder. A figure of cable operating temperature distributions for some typical lines, L1, L31 and L50, is shown in Fig.6 based on their thermal modelling and loading described by Sc-2. Fig.6 also shows the mean value of temperature profiles and the percentile in different temperature ranges. The transient thermal model is utilized for the calculation of thermal profiles (Fig. 6) here due to its accuracy.

The results in Fig. 6 show that each cable has its own operating thermal profile depending on its current loading, cable and ducting system properties and environmental (soil) thermal conditions is installed in. In this test network, all cables are modelled with the same cable properties and environmental conditions and therefore their thermal profiles totally depend on the current loading. Since most feeders have the same load demand, except F4, $L 1$ and $L 50$ experience almost the same thermal profiles as seen in Fig. 6. $L 1$ and $L 50$ operate at around $83 \%$ of the time between $27^{\circ} \mathrm{C}$ and $40^{\circ} \mathrm{C}$, while only $13 \%$ of the time is above $40^{\circ} \mathrm{C}$ and $3 \%$ of the time at very low temperatures (below $27^{\circ} \mathrm{C}$ ).

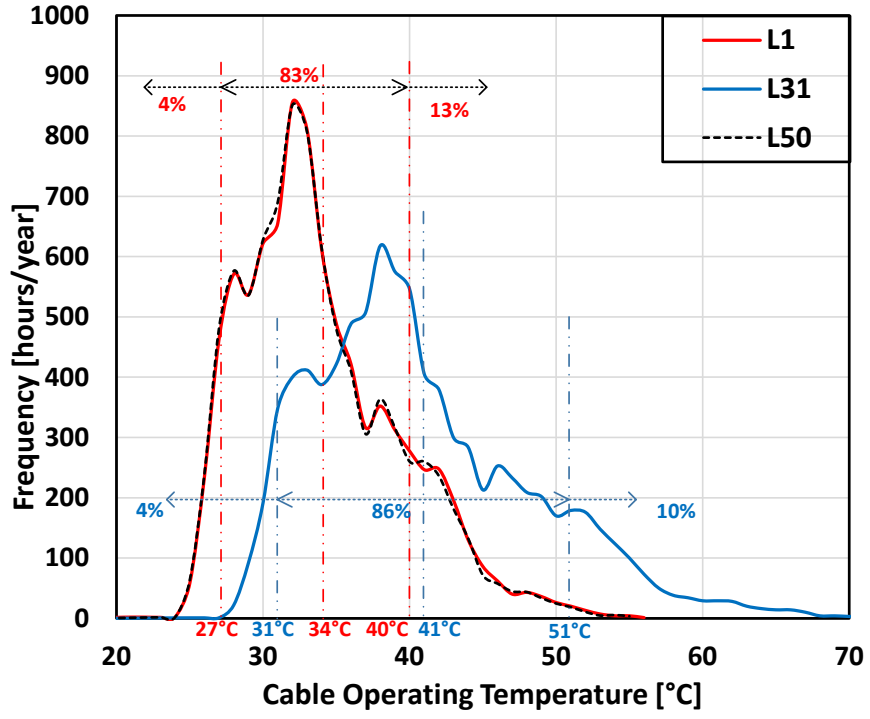

Figure 6. Temperature Distribution of $L 1, L 31$ and $L 50$ for Sc-2

It can also be observed that $L 31$ has a significantly higher operating temperature than the other two cables. The mean value of $L 31$ is $7^{\circ} \mathrm{C}$ higher than that of $L 1$ and $L 50$. The maximum operating temperature of $L 31$ is $73^{\circ} \mathrm{C}$ which is substantially higher than the $55^{\circ} \mathrm{C}$ of $L 1$ and $L 50 . L 31$ has an operating duration of $86 \%$ (7534 hours) of a year between $31^{\circ} \mathrm{C}$ and $51^{\circ} \mathrm{C}$, only $4 \%$ below $31^{\circ} \mathrm{C}$ and $10 \%$ above $51^{\circ} \mathrm{C}$. This indicates $L 31$ has an increased thermal and current loading compared to the other two cables.

In reality, the cable and ducting system properties and environmental (soil) conditions for each cable could be obtained and fed into this methodology. Some unfavourable thermal conditions, such as dry soil or rock, mutual heating between cables, and road crossing, may cause some "hotspots" along the cables and change their thermal profiles. However, this will not affect majorly the thermal loading of the cables as the duration of the cables that operate between the $90^{\circ} \mathrm{C}$ and $130^{\circ} \mathrm{C}$ is very limited (around 90 hours).

The thermal ageing of each cable can be calculated based on its thermal profile. The most aged cables are identified as the most critical lines in the network which usually require more maintenance and earlier replacement. Different emergency rating levels could result in different operating thermal profiles and thus ageing of the cables. Therefore, this approach could help utilities to achieve a suitable balance between system reliability and the cost of cable ageing and maintenance.

\section{CONCLUSION}

This paper proposes an electro-thermal modelling of UGCs into a wide network reliability evaluation. It allows capturing cable and ducting system properties in combination with cable emergency ratings implementation within reliability assessment modelling.

The results suggest that cable emergency rating can enhance the network's loadability and flexibility during emergency operations. Therefore it significantly improves the overall network reliability performance. It also provides the 
possibility to increase the utilization of network infrastructure and to defer network reinforcement. Based on the output operating thermal profiles of the cables examined in the 4-bus RBTS, it is suggested that the cable conductor temperatures are slightly increased due to the emergency rating. This however has a small impact on cable ageing since the operation of the cable above $90^{\circ} \mathrm{C}$ does not exceed the 90 hours per year. The proposed methodology has some limitations and should be further improved in future work to help utilities to capture a suitable balance between system reliability worth and cost of cable ageing and maintenance.

The comparison of the steady state and transient thermal modelling approaches has a significant impact when emergency thermal loading is considered. This is important for capturing accurately the cable operating thermal profile under emergency events due to their intermittent loading and short duration. Under the transient thermal modelling the thermal overloading indicated zero duration of operation of the cable above $90^{\circ} \mathrm{C}$. Therefore, no effect on ageing is expected when more accurate thermal modelling is implemented.

\section{REFERENCES}

[1] L. Bertling, R. Allan, and R. Eriksson, "A reliability-centered asset maintenance method for assessing the impact of maintenance in power distribution systems," IEEE Transactions on Power Systems, vol. 20, pp. 75-82, 2005.

[2] G. Mazzanti, "Analysis of the Combined Effects of Load Cycling, Thermal Transients, and Electrothermal Stress on Life Expectancy of High-Voltage AC Cables," IEEE Transactions on Power Delivery, vol. 22, pp. 2000-2009, 2007.

[3] R. S. Olsen, J. Holboll, and U. S. Gudmundsdottir, "Dynamic temperature estimation and real time emergency rating of transmission cables," in 2012 IEEE Power and Energy Society General Meeting, 2012, pp. 1-8.

[4] G. Mazzanti, "The combination of electro-thermal stress, load cycling and thermal transients and its effects on the life of high voltage ac cables," IEEE Transactions on Dielectrics and Electrical Insulation, vol. 16, pp. 1168-1179, 2009.

[5] Y. C. Liang and Y. M. Li, "On-line dynamic cable rating for underground cables based on DTS and FEM," WSEAS Trans. Cir. and Sys., vol. 7, pp. 229-238, 2008.

[6] R. Olsen, J. Holboell, and U. S. Gudmundsdottir, "Electrothermal Coordination in Cable Based Transmission Grids," IEEE Transactions on Power Systems, vol. 28, pp. 4867-4874, 2013.
"IEEE Recommended Practice for Protection and Coordination of Industrial and Commercial Power Systems (IEEE Buff Book)," IEEE Std 242-2001 (Revision of IEEE Std 242-1986) [IEEE Buff Book], pp. 1-710, 2001.

[8] "IEC Standard 60853-2: Calculation of the cyclic and emergency current rating of cables - Part 2: Cyclic rating of cables greater than 18/30 (36) $\mathrm{kV}$ and emergency ratings for cables of all voltages," ed: International Electrotecnical Commission, 1989.

[9] G. Parise and G. Rubino, "A comparison of the ANSI/IEEE and the CENELEC/IEC approaches to overload protection of insulated power cables," IEEE Transactions on Industry Applications, vol. 33, pp. 1362-1366, 1997.

[10] M. M. Jensen, "Overload Capacity of Polymer Insulated Medium Voltage Cables," Master, Department of Electrical Engineering, Technical Institution of Denmark (DTU), Lyngby, Denmark, 2011.

[11] W. Z. Black and P. Sang-il, "Emergency Ampacities of Direct Buried Three Phase Underground Cable Systems," IEEE Transactions on Power Apparatus and Systems, vol. PAS-102, pp. 2124-2132, 1983.

[12] K. Kopsidas, C. Tumelo-Chakonta, and C. Cruzat, "Power Network Reliability Evaluation Framework Considering OHL Electro-Thermal Design," IEEE Transactions on Power Systems, vol. PP, pp. 1-9, 2015

[13] M. Buhari and K. Kopsidas, "Probabilistic assessment of impacts of real-time line ratings on distribution networks," in 2014 International Conference on Probabilistic Methods Applied to Power Systems (PMAPS), 2014, pp. 1-6.

[14] A. Safdarian, M. Z. Degefa, M. Fotuhi-Firuzabad, and M. Lehtonen, "Benefits of Real-Time Monitoring to Distribution Systems: Dynamic Thermal Rating," IEEE Transactions on Smart Grid, vol. 6, pp. 2023-2031, 2015.

[15] R. Billinton and R. N. Allan, Reliability evaluation of power systems, 2nd ed. NEW YORK AND LONDON: PLENUM PRESS, 1996.

[16] R. Billinton and W. Li, Reliability Assessment of Electrical Power Systems Using Monte Carlo Methods. London: Springer, 1994.

[17] M. Diaz-Aguilo, F. De Leon, S. Jazebi, and M. Terracciano, "Ladder-Type Soil Model for Dynamic Thermal Rating of Underground Power Cables," IEEE Power and Energy Technology Systems Journal, vol. 1, pp. 21-30, 2014.

[18] R. N. Allan, R. Billinton, I. Sjarief, L. Goel, and K. S. So, "A reliability test system for educational purposes-basic distribution system data and results," IEEE Transactions on Power Systems, vol. 6, pp. 813-820, 1991.

[19] P. Wong, P. Albrecht, R. Allan, R. Billinton, Q. Chen, C. Fong, et al., "The IEEE Reliability Test System-1996. A report prepared by the Reliability Test System Task Force of the Application of Probability Methods Subcommittee," IEEE Transactions on Power Systems, vol. 14, pp. 1010-1020, 1999. 